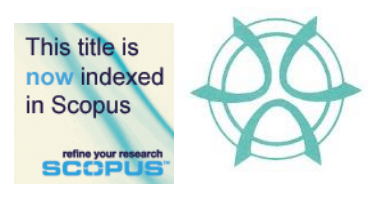

PLANNING MALAYSIA:

Journal of the Malaysian Institute of Planners

SPECIAL ISSUE V (2016), Page 39 - 48

\title{
DEMOGRAPHIC TRANSITION AND SUSTAINABLE COMMUNITIES IN MALAYSIA
}

\author{
Hanan Elsawahli ${ }^{1}$, Faizah Ahmad ${ }^{2} \&$ Azlan Shah Ali $^{3}$ \\ ${ }^{1,2}$ Centre for Sustainable Urban Planning \& Real Estate \\ ${ }^{3}$ Centre for Building, Construction \& Tropical Architecture \\ Faculty of Built Environment \\ UNIVERSITY OF MALAYA
}

\begin{abstract}
As a developing country, Malaysia is undergoing a demographic transition from a high fertility and mortality rural society towards an industrialised society with low fertility and mortality rates. This transition involved an increased growth rate of elderly population. The number of elderly has risen from 1.4 million in 2000 to 2.1 million in 2010 and is projected to be 3.4 million by 2020 . A population aging needs to accumulate assets in order to achieve sustainable development goals. This represents the main challenge to planners and policy makers in terms of designing aged-friendly neighbourhoods to meet the elderly needs. This paper aims to review the population aging trends and policy framework available for the elderly in Malaysia. The paper further discusses the sustainable neighbourhoods related to active aging. The paper concludes by identifying fundamental gaps in both knowledge and policy associated with planning for the aging population and successful aging.
\end{abstract}

Keyword: Demographic transition, aging population, policy framework, active aging. 
Hanan Elsawahli, Faizah Ahmad \& Azlan Shah Ali

Elderly Policy Framework and Active Aging in Malaysia

\section{INTRODUCTION}

Population aging has been a phenomenon of developed industrialized countries since the early 70s, as it is believed to be the result of improved medical care and good nutrition. Researchers have argued that population aging is a result of low fertility and increased longevity (Bengtson, Gans, Putney, \& Silverstein, 2009; Crawford, 2010; Gardner, 2011). As a result, developing countries are currently experiencing a significant increase in the percentage of its elderly population. Malaysia being a fast developing country has been much concerned to adapt its government policies to meet the needs of its elderly population in order to achieve sustainable development goals.

As a developing country, Malaysia is undergoing a demographic transition from a high fertility and mortality rural society towards an industrialised society with low fertility and mortality rates. This transition involved an increased growth rate of elderly population. Malaysians elderly population is increasing; older people represent $7.7 \%$ of the total population (Table 1). This demographic transition has implications for sustainable development goals. Hence, the objectives of this paper are:

1. To review policy framework available for elderly in Malaysia.

2. To examine the impact of neighbourhood design on active aging.

Table 1: Population percentage in major age group, Malaysia

\begin{tabular}{llllll}
\hline Age Group & $\mathbf{1 9 7 0}$ & $\mathbf{1 9 8 0}$ & $\mathbf{1 9 9 1}$ & $\mathbf{2 0 0 0}$ & $\mathbf{2 0 1 0}$ \\
\hline $0-14$ & 44.9 & 39.6 & 36.7 & 33.5 & 27.6 \\
$15-44$ & 40.7 & 45.6 & 47.6 & 48.8 & 50.17 \\
$45-59$ & 9.2 & 9.2 & 9.9 & 11.6 & 14.25 \\
$60-74$ & 4.4 & 4.6 & 4.6 & 5.0 & 6.25 \\
$75^{+}$ & 0.8 & 1.1 & 1.2 & 1.3 & 1.5 \\
\hline
\end{tabular}

Source: Department of Statistics, Malaysia, 2010

\section{METHODOLOGY}

The study involves both qualitative and quantitative approaches. The qualitative approach included review of elderly trend, housing provision for the elderly and initiatives for elderly using government data from Department of Statistics, Dewan Bandaraya Kuala Lumpur (DBKL) and Dewan Bandaraya Ipoh (DBI). This also involved review of empirical research on the association between active aging and characteristics of the built environment. The quantitative approach involved a pilot study examining the relationship between neighbourhood environmental factors and active aging. 
PLANNING MALAYSIA

Sustainable Urban Development

\section{RESEARCH BACKGROUND}

This section includes a review of housing provision for the elderly, initiatives for the elderly, policy framework in Malaysia and empirical research on elderly and the built environment.

\section{Housing Provision for the Elderly}

Malaysia has formulated its housing policies since the pre-independent period until the latest Tenth Malaysia Plan (2011-2015). However, the housing needs for the elderly have attracted less attention. Sulaiman, Baldry and Ruddock (2006) argued that elderly housing needs are not met as the housing programme in Malaysia does not include provision of housing for the elderly. The Ministry of Women, Family and Community Development provides homes for the elderly who are frail, with no other social housing alternatives available for the young olds. This greatly affected the living arrangement of the elderly. In Malaysia, the different ethnic groups have different living arrangements for the elderly according to the different socio-economic and cultural backgrounds. However, the structure of Malaysian families is shifting, with a growing trend towards smaller nuclear families. Such living arrangements have implications for planning and preparing adequate services, as it shows that the role of family as the main caregiver of the elderly is declining. Table 2 shows the continued decline in the average household size over the past four decades. This will result in the social isolation of the elderly and a financial burden on the government. Thus policies should focus on providing adequate housing with the necessary services and facilities for the elderly to live independently as it outlines their quality of life and reflects consistency of sustainable development with the demographic transition.

Table 2: Average household size, Malaysia

\begin{tabular}{lllll}
\hline Household Type & $\mathbf{1 9 8 0}$ & $\mathbf{1 9 9 1}$ & $\mathbf{2 0 0 0}$ & $\mathbf{2 0 1 0}$ \\
\hline Average household size & 5.2 & 4.8 & 4.6 & 4.5 \\
Percentage of nuclear family household & 55.2 & 59.9 & 65.2 & 70.3 \\
\hline
\end{tabular}

Source: Department of Statistics, 2010

Furthermore, there could be some factors influencing the Malaysian elderly to stay in their place of residence after retirement, such as the uneven increase in housing prices among the different states in Malaysia. It is evident that the housing prices differ according to location and physical attributes (Fig. 1). Despite the fact that Malaysian housing policies are formulated to ensure that all Malaysians have access to affordable and adequate shelter $\left(7^{\text {th }}\right.$ Malaysia Plan, $8^{\text {th }}$ Malaysia Plan, $9^{\text {th }}$ Malaysia Plan $\& 10^{\text {th }}$ Malaysia Plan), the Housing Price Index in Malaysia showed an increase of $75 \%$ (Valuation and Property Services Department, 2010). 
Hanan Elsawahli, Faizah Ahmad \& Azlan Shah Ali

Elderly Policy Framework and Active Aging in Malaysia

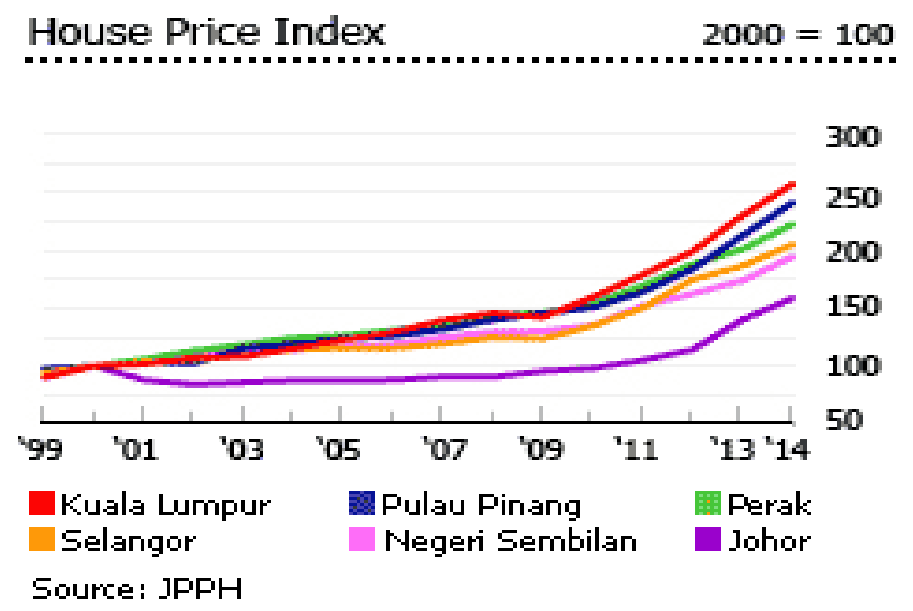

Figure 1: Housing prices by state, Malaysia

Source:www.globalpropertyguide.com > Asia > Malaysia

\section{Initiatives for the Elderly in Malaysia}

The Malaysian government has put great efforts and formulated policies for the welfare of its older adults and has been generally successful at both international and national level. At the international level, Malaysia has supported and participated in many programs, conferences and seminars in response to the United Nations 18 Principles of Older Persons (resolution 46/91) and the international plans of action on aging, such as:

- The Macao Plan of Action on Aging (1999).

- The World Assemblies on Aging Spain (2002).

- The Shanghai Implementation Strategy (2002) for the region.

- $5^{\text {th }}$ Asian and Pacific Conference Plan of action on Population and Poverty in Bangkok, 2002.

At the national level, Malaysia held many conferences and seminars to gather the necessary information and draw recommendations in planning for her aging population, for example:

- The National Social Welfare Policy formulated in 1990, identifying the role of families and communities as the main caregivers for the elderly.

- In 1990, Malaysia launched the Caring Society project to discuss caring issues including issues of elderly care.

- In 1992, the first of October was announced as the National Day for the Elderly coinciding with the International Day of Older Persons.

- In 1993, Malaysia formulated the Care Centre Act to ensure that the elderly care centres and institutions are to standards and meeting the minimum requirement for elderly care. 
- The National Policy for the Elderly formulated in 1995 aimed at:

"To establish a society of the elderly, who are contented, dignified, possessed of a high sense of self-worth, and optimizing their potential, as well as to ensure that they enjoy all opportunities besides being given the care and protection as members of a family, society and the nation"

The policy had three objectives that included encouraging the respect for the elderly in family, society and nationwide, capitalize on the potential on the elderly potentials to remain active and productive and the provision of the necessary facilities to care for and protect them. These objectives initiated a number of action plans and six sub-committees (religion and training, education, health, housing, research and publicity). In line with these, several programs were started and planned. Item 6 of the Action Plan (1996) acknowledged that "Existing and future houses should include facilities suitable for the elderly to enable them to live comfortably."

Both the National Policy for the Elderly and the Action Plan are reviewed every ten years after 2005 .

- In 1996, the National Advisory and Consultative Council for the Elderly (NACCE) was formed to draw recommendations to assist the government in responding effectively to the phenomenon of population aging.

- In 1996, The Elderly Health Care Program was introduced by the Ministry of Health and established the National Health Council for the Elderly (NHCE).

In 2011 the National Policy for Older Persons (NPOP) and the Action Plan (2010-2020) replaced the National Policy for the Elderly (NPE) 1995 and the Action Plan 1996.

\section{Gaps in the National Policy for the Elderly (NPE)}

The National Policy for the Elderly (NPE) was a good step in considering the changing demographics in Malaysia and is a milestone in providing care and meeting the needs for the frail elderly resulting in 15-day care centres built throughout the country. Nevertheless, there are some gaps;

- The action plan (1996) did not cover adequately the housing needs for the young old (active elderly aged 60-75).

- The policy emphasized on social aspects and provisions for the frail elderly and is wedded to traditional theories of how to care for them, rather than reflecting the present status of the elderly, denying the housing needs of the active urban elderly in the process.

- The elderly active lifestyle is mentioned in objective 1 in the Health care Program for the Elderly and not in the housing program:

"To improve the health of older persons to enable them to lead and enjoy full and active lives through promotive and preventive health care" 
Hanan Elsawahli, Faizah Ahmad \& Azlan Shah Ali

Elderly Policy Framework and Active Aging in Malaysia

The Tenth Malaysia Plan (10MP, 2011-2015)

The Tenth Malaysia Plan was tabled in June 2010 and introduced the programs needed to achieve the vision 2020 objectives, aimed at making Malaysia a developed and competitive country. The plan is based on ten concepts further interpreted into ten main premises. To achieve these concepts, five key strategic thrusts are identified. The fifth thrust relates to planning for the elderly:

The fifth thrust states:

"Building an environment that enhances quality of life"

This includes measures to ensure that the elderly will stay active, productive and healthy as they age. The programs will focus on:

- Enhancing aged-friendly infrastructure.

- Improving access to affordable health care.

- Ensuring provision of adequate housing.

- Improving financial security.

- Improving employment opportunities.

The programs aim at involving the senior citizens in both social and economic activities by covering different domains that include transport, healthcare, housing, financial security and work participation.

The government seems to be committed to promoting healthy aging. The plans provide the broad framework for preparing and planning for the aging population and emphasis should be on the implementation mechanisms that ensure meeting the objectives of the plans. Proper and continuous monitoring of services and activities is of equal importance to put the plans in place.

\section{Elderly and Sustainable Built Environment}

Sustainable development that advocate walkable neighbourhoods in relation to physical activity have, for many years, attracted the attention of the urban planning profession. Assuming that active aging is influenced by neighbourhood characteristics, sustainable development goals view neighbourhood design as a means to enhance and maintain the older individual's access to activities (Michael, Green, \& Farquhar, 2006; Satariano, 2010). Li et al. (2005) examined the relationship between the built environment and the walking activity of the elderly at both residential and neighbourhood levels. His results showed that there was a positive relationship between the built environment factors and the walking activity of older people. Similarly, Kaczynski, Potwarka, Brian and Saelens (2008) argued that the neighbourhood environmental attributes are associated with the active lifestyle of the residents. They found that residents who moved to the neighbourhood designed to promote walkability showed improved social interaction, physical activity and hence improved health. 
On the other hand, Dumbaugh (2008) and Mendes de Leon et al. (2009) argued that the perception of their neighbourhood safety (heavy traffic, crime rate) influences the walkability of older adults. Another study supporting the above findings is the study by Dill et al. (2010) who studied the influence of green streets on the elderly physiological health found that vibrant streets with street furniture encouraged walkability and promoted social interaction.

\section{THE PILOT STUDY}

\section{Target Population}

100 respondents residing in Taman Meru, Ipoh, were pilot-studied. The area was selected based on the fact that Perak is the state with a high elderly population. According to the United Nations age $60^{+}$is considered the age for addressing aging issues. The study focused mainly on the active aging among the older adults aged 60-75 years in residential areas. However, the study also included other age group under 60: $\left(45^{+}\right)$, to consider changes in active aging needs as people age.

\section{Research Variables}

The research is conducted to cast light on active aging provided by certain neighbourhood variables. Active aging is promoted by enhancing social interaction (Chan, To, \& Chan, 2006), and physical activity (Handy, Cao, \& Mokhtarian, 2008; Rohe, 2009) Table 3.

Dependent Variables: Active Aging Independent Variables: Neighbourhood Design

Table 3: Research variables

\begin{tabular}{lc}
\hline Dependent Variables & Independent Variables \\
\hline Active Aging Variables: & Neighbourhood design: \\
Physical Activity & 1. Walking, \\
Social Interaction & 2. Physical facilitators to walking, \\
& 3. Physical barriers to walking, \\
& 4. Convenience, \\
& 5. Accessibility, \\
& 6. Permeability, \\
& 7. Maintenance and \\
& 8. Safety \\
\hline
\end{tabular}

\section{MAIN SURVEY}

A face-to-face questionnaire was administered on 100 residents aged 45-75 years residing in Taman-Meru, Ipoh. The research employed five items to measure each variable. To avoid lengthy questionnaires that might impact response, the questionnaire was divided into three sections. The first section included the dependent variables. The second section included the independent variables. All 
Hanan Elsawahli, Faizah Ahmad \& Azlan Shah Ali

Elderly Policy Framework and Active Aging in Malaysia

questions consisted of five items and based on five-point Likert format. The third section included the demographic characteristics

\section{Data Analysis}

The data was analysed using the Statistical Package for Social Science (SPSS) version 16. The analysis included inferential statistics to address casual relations between the variables. This involved the use of Spearman's (rho) correlation to measure the strength and direction of the relationship between active aging and the neighbourhood design variables.

\section{Sample Characteristics}

The socio-economic characteristics of the residents show that the majority of the respondents stayed more than 10 years in the neighbourhood, and owned their own homes. There was a prevalence of male and married respondents, $70 \%$ aged 56 and above, and the majority had received at least a high school education and had an income level above RM4000.

The researchers further examined the correlation between the dependent variables and the independent variables (Table 4). All factors showed moderategood correlations with active aging except for walking with physical activity $(0.191, p>0.05=0.057)$ and convenience with both social interaction and physical activity $(-0.006 \quad p>0.05=0.95 ;-0.023 p>0.05=0.823)$ in Taman Meru neighbourhood (Table 4).

Table 4: Correlation coefficients of active aging variables and neighbourhood design variables

\begin{tabular}{llll}
\hline $\begin{array}{l}\text { Neighbourhood } \\
\text { factors }\end{array}$ & Environmental & TM $(\mathbf{n}=\mathbf{1 0 0})$ & \\
\cline { 2 - 4 } & $\begin{array}{l}\text { Social Interaction }(\boldsymbol{p}- \\
\text { value })\end{array}$ & $\begin{array}{l}\text { Physical } \\
\text { value })\end{array}$ \\
\hline Walking & $0.201^{* * *}(0.045)$ & $0.191(0.057)$ \\
Facilitators to Walking & $0.342^{* *}(0.001)$ & $0.329^{* *}(0.001)$ \\
Barriers to walking & $-0.203^{*}(0.04)$ & $-0.247^{*}(0.01)$ \\
Convenience & $-0.006(0.95)$ & $-0.023(0.823)$ \\
Accessibility & $0.211^{*}(0.035)$ & $0.246^{*}(0.014)$ \\
Permeability & $0.707^{* *}(0.000)$ & $0.637^{* *}(0.000)$ \\
Maintenance & $0.826^{* *}(0.000)$ & $0.775^{* *}(0.000)$ \\
Safety & $0.955^{* *}(0.000)$ & $0.846^{* *}(0.000)$ \\
\hline
\end{tabular}

\section{DISCUSSION}

The purpose of the study is to provide an understanding of the demographic transition and sustainable development in Malaysia and to explore the neighbourhood environmental factors influencing the sustainability of elderly active aging. The overall trends of senior citizens in Malaysia show an ever increasing aging population that will grow at a quicker pace over the coming 
PLANNING MALAYSIA

Sustainable Urban Development

decades. As the Malaysian population has aged it became vitally important to consider the consequences of the older population on public policy. The study identified important gaps in knowledge; the first gap is the lack of data on the residential mobility of the elderly at retirement age. The second gap is the linkage between elderly residential mobility and the occurrence of life events (retirement) and health events (declined functional ability). The study also identified the gaps in the National Policy for the elderly; the first gap is the inadequate coverage of active elderly housing needs. The second gap is the focus on social aspects and provisions for the frail elderly and negligence of the young olds needs. The third gap is the emphasis on health programs to promote healthy aging rather than neighbourhood planning and design. Moreover, the study also identified a gap in physical planning literature for healthy aging. Little research recognized the association between neighbourhood environmental factors and healthy aging, with most research dominated by psychological and biological perspectives. The promotion of an active lifestyle through neighbourhood design remain greatly under researched. Jacobs (1961) wrote:

"Failing or failed city areas are in trouble not so much of what they have (which can always be regarded as a base to build upon), but because of what they lack).(Jacobs, 1961, pp. 176-177).

The initiatives introduced by the government in addressing the needs of the aging population have been very successful for the frail elderly, but lacked consideration for the young olds. A comprehensive planning of aged friendly neighbourhoods is required to address the increasing needs of healthy aging among the elderly.

The pilot survey results provided essential insights into the neighbourhood environmental factors that are most related with active aging and highlighted the impact of certain neighbourhood environmental variables on active aging.

\section{CONCLUSION}

The purpose of the study is to weave together a literature on aging trend in Malaysia and examine association between neighbourhood designs with elderly active aging. In Malaysia, the highlighted fact is that the elderly lack good neighbourhood design that promotes healthy aging. Hence, the challenge facing Malaysian planners and architects is to create neighbourhoods that are sustainable to provide quality services and care for the aging population and thus, achieve the objectives of the vision 2020 .

\section{ACKNOWLEDGEMENTS}

This research is supported by University of Malaya IPPP: LL008-15SUS 
Hanan Elsawahli, Faizah Ahmad \& Azlan Shah Ali

Elderly Policy Framework and Active Aging in Malaysia

\section{REFERENCES}

Bengtson, V. L., Gans, D., Putney, N. \& Silverstein, M. (2009). Handbook of theories of aging ( $2^{\text {nd }}$ Edition). New York, NY: Springer.

Chan, J., To, H.-p. \& Chan, E. (2006). Reconsidering social cohesion: developing a definition and analytical framework for empirical research. Social Indicators Research, 75, 273-302.

Crawford, J. (2010). Health at the heart of spatial planning. Planning Theory \& Practice, 11(1), 91-113

Dill, J., Neal, M., Shandas, V., Luhur, G., Adkins, A. \& Lund, D. (2010). Demonstrating the Benefits of Green Streets for Active Aging: Final Report to EPA. Portland, OR: Centre of Urban Studies, Portland State University.

Dumbaugh, E. (2008). Designing communities to enhance the safety and mobility of older adults: a universal approach. Journal of Planning Literature, 23(1), 17-36.

Gardner, P. J. (2011). Natural neighborhood networks - important social networks in the lives of older adults aging in place. Journal of Aging Studies, 25, 263-271.

Handy, S. L., Cao, X. \& Mokhtarian, P. L. (2008). The casual influence of neighbourhood design on physical activity within the neighbourhood: evidence from Northern California. American Journal of Health Promotion, 22(5), 350-358.

Jacobs, J. (1961). The Death \& Life of Great American Cities. New York: Random House, New York

Kaczynski, A. T., Potwarka, L. R., Brian, E. \& Saelens, B. E. (2008). Innovations in design and analysis: association of park size, distance, and features with physical activity in neighborhood parks. American Journal of Public Health, 98(8), 1451-1456.

Li, F., Fisher, K. J., Bauman, A., Ory, M. G., Chodzko-Zajko, W. \& Harmer, P. et al. (2005) Neighbourhood influences on physical activity in middle-aged and older adults: a multilevel perspective. Journal of Aging and Physical Activity, 13(1), 87-114.

Mendes de Leon, C.F., Lagney, K.A., Biericas, J.L., Barnes, L.L., Skarupski, K.A., Scherr, P.A. \& Evans, D.A. (2009). Neighbourhood social cohesion and disorder in relation to walking in community-dwelling older adults: a multi-level analysis. Aging Health 21(1), 155-171.

Michael, Y. L., Green, M. K. \& Farquhar, S. A. (2006). Neighborhood design and active aging. Health \& Place, 12(4), 734-740.

Rohe, W. M. (2009). From local to global: one hundred years of neighbourhood planning. Journal of the American Planning Association, 75(2), 209-230.

Satariano, W. A. (2010). Lower-body function, neighbourhoods, and walking in an older population. American Journal of Preventive Medicine, 38, 419-428.

Sulaiman, N., Baldry, D. \& Ruddock, L. (2006). Issues concerning housing for the elderly in Malaysia. Paper presented at the 6th International Postgraduate Research Conference. April 6-7, 2006, Delft University of Technology.

The Economic Planning Unit (2010). Tenth Malaysia Plan 2011-2015. Putrajaya: Prime Minister's Department. https://www.pmo.gov.my/dokumenattached/RMK/ RMK10_Eds.pdf.

Valuation and Property Services Department (2010). Malaysia House Price Index (2007-Q1 2011). Retrieved $25^{\text {th }}$ October, 2011. 